\title{
Repeated call types in Hawaiian melon-headed whales (Peponocephala electra)
}

\author{
Maxwell B. Kaplan, ${ }^{\text {a) }}$ T. Aran Mooney, and Laela S. Sayigh \\ Biology Department, Woods Hole Oceanographic Institution, MS\#50, 266 Woods Hole Road, Woods Hole, \\ Massachusetts 02543 \\ Robin W. Baird \\ Cascadia Research Collective, 218 1/2W, 4th Avenue, Olympia, Washington 98501
}

(Received 8 April 2014; revised 10 July 2014; accepted 14 July 2014)

\begin{abstract}
Melon-headed whales are pantropical odontocetes that are often found near oceanic islands. While considered sound-sensitive, their bioacoustic characteristics are relatively poorly studied. The goal of this study was to characterize the vocal repertoire of melon-headed whales to determine whether they produce repeated calls that could assist in recognition of conspecifics. The first tag-based acoustic recordings of three melon-headed whales were analyzed. Tag records were visually and aurally inspected and all calls were individually extracted. Non-overlapping calls with sufficient signal-to-noise were then parameterized and visually grouped into categories of repeated call types. Thirty-six call categories emerged. Categories differed significantly in duration, peak and centroid frequency, and $-3 \mathrm{~dB}$ bandwidth. Calls of a given type were more likely to follow each other than expected. These data suggest that repeated calls may function in individual, subgroup, or group recognition. Repeated call production could also serve to enhance signal detection in large groups with many individuals producing simultaneous calls. Results suggest that caution should be used in developing automatic classification algorithms for this species based on small sample sizes, as they may be dominated by repeated calls from a few individuals, and thus not representative of species- or population-specific acoustic parameters. (C) 2014 Acoustical Society of America.
\end{abstract}

[http://dx.doi.org/10.1121/1.4892759]

PACS number(s): 43.80.Ka, 43.30.Sf [WWA]

Pages: 1394-1401

\section{INTRODUCTION}

Animals rely on detection and recognition mechanisms for finding and identifying conspecifics. Recognition can operate on many levels and can include species, population, group, kin, and individual identification (Bradbury and Vehrencamp, 1998). These mechanisms may be particularly important for social marine species that need to find others after becoming temporarily separated (Janik and Slater, 1998; Janik, 2005).

Many delphinids live in societies where animals can form strong social bonds (Mann, 2000). Multiple species use individual-specific calls to encode their identity and to contact and identify other individuals (Janik, 2009), such as the well-studied common bottlenose dolphin (Tursiops truncatus). The individually distinctive signature whistle of the common bottlenose dolphin (Caldwell and Caldwell, 1965; Caldwell et al., 1990) develops through vocal production learning (Janik and Sayigh, 2013) and can stay stable over periods of at least a decade (Sayigh et al., 1990). While the absolute frequencies, duration, and intensity of signature whistles may vary with context (Caldwell et al., 1990), it is the frequency modulation pattern, or contour, of the whistle that conveys the identity of the caller (Janik et al., 2006). Signature whistles function in individual recognition (Sayigh et al., 1999), maintaining group cohesion (Janik and Slater,

\footnotetext{
a) Author to whom correspondence should be addressed. Electronic mail: mkaplan@whoi.edu
}

1998), and in mediating joining of groups in the wild (Quick and Janik, 2012).

Other delphinids that have been reported to produce signature whistles include Indo-Pacific bottlenose dolphins (Tursiops aduncus) (Gridley et al., 2014), short-beaked common dolphins (Delphinus delphis) (Caldwell and Caldwell, 1968), Atlantic spotted dolphins (Stenella frontalis) (Caldwell et al., 1973), and Indo-Pacific humpback dolphins (Sousa chinensis) (Van Parijs and Corkeron, 2001). Repeated call types have been reported in other delphinid species, including the Guiana dolphin (Sotalia guianensis) (de Figueiredo and Simao, 2009), northern right whale dolphin (Lissodelphis borealis) (Rankin et al., 2007), and short-finned pilot whale (Globicephala macrorhyncus) (Sayigh et al., 2013), but it is not known whether any are individually specific. In both short-finned pilot whales and fish-eating "resident" killer whales (Orcinus orca), at least some calls are shared within a population (Ford, 1989; Sayigh et al., 2013), perhaps as a result of their close-knit matrilineal social structure (Yurk et al., 2002). Some non-delphinid odontocete species have also been shown to produce stereotyped calls, such as narwhals (Monodon monoceros) (Shapiro, 2006), sperm whales (Physeter macrocephalus) (Antunes et al., 2011), and belugas (Delphinapterus leucas) (Morisaka et al., 2013), although the functions of these calls are not fully understood. Overall, the vocal repertoires of most odontocete species have not been studied extensively. The goal of this study was to begin to characterize the vocal repertoire of one 
relatively unstudied delphinid species, the melon-headed whale (Peponocephala electra).

Melon-headed whales are found throughout the tropics and subtropics, primarily from $20^{\circ} \mathrm{N}$ to $20^{\circ} \mathrm{S}$ (Jefferson and Barros, 1997). These delphinids often live in pelagic waters but may also be closely associated with oceanic islands (Jefferson and Barros, 1997; Brownell et al., 2009; Aschettino et al., 2012). Two partially sympatric populations have been identified in Hawai'i: the Kohala Resident Population (KRP), which primarily inhabits the relatively shallow waters off the northwest coast of Hawai'i Island, and the Hawaiian Islands population (HIP), which is found in deeper waters around the main Hawaiian Islands and offshore (Aschettino et al., 2012; Woodworth et al., 2012). Although the two populations partially overlap, they are not known to mix, and an analysis of association patterns of photo-identified individuals indicates they are likely demographically independent (Aschettino et al., 2012).

In spite of this species' wide distribution, little is known about its behavior. Melon-headed whales have been observed resting near shore during the day and are thought to forage in deeper waters at night (Brownell et al., 2009), potentially for small schooling fish (Sekiguchi et al., 1992; Jefferson and Barros, 1997) and mesopelagic squid (Jefferson and Barros, 1997). While resting, small groups appear to coalesce into larger groups, suggesting that at least some populations may live in fission-fusion societies (Jefferson and Barros, 1997; Brownell et al., 2009; Frankel and Yin, 2010). Melon-headed whales are considered to be potentially sensitive to sound, with one near-mass stranding event in Hawaiian waters associated with mid-frequency naval sonar nearby (Southall et al., 2006; Brownell et al., 2009), and a mass stranding in Madagascar associated with a mid-frequency multi-beam mapping sonar (Southall et al., 2013).

The melon-headed whale acoustic repertoire has been described to include clicks, burst-pulsed sounds, and whistles (Watkins et al., 1997; Frankel and Yin, 2010). However, the results presented here indicate that melon-headed whales can produce calls that fall along a continuum of pulsed to tonal signals, as have been found in short-finned pilot whales and false killer whales (Pseudorca crassidens) (Murray et al., 1998; Sayigh et al., 2013). Thus, all sounds are referred to as "calls" (after Sayigh et al., 2013).

Frankel and Yin (2010) described the temporal characteristics of melon-headed whale echolocation clicks and the spectral and temporal characteristics of burst-pulse sounds and whistles. The authors noted considerable variation in the spectral parameters of melon-headed whale whistles, suggesting the potential for a diversity of call types in their recordings (Frankel and Yin, 2010), although it was not within the scope of their study to examine whether repeated call types occurred. However, this is an important issue when attempting to describe species-specific call characteristics. For example, a recording dominated by repeated calls from a small number of individuals will produce biased measurements of call parameters. Our study addresses this concern by examining whether melon-headed whales produce repeated calls, and if so, whether calls are shared within groups or populations. Such information has important implications not only for passive acoustic monitoring, but also for our understanding of odontocete communication and social structure.

\section{METHODS}

\section{A. Data collection}

Four $\sim 1$-month long expeditions were carried out between 2011-2013 with the primary objective to deploy tags and record the acoustic signals of melon-headed whales and false killer whales. Observations and tagging were conducted from an $8.2 \mathrm{~m}$ Boston Whaler equipped with two $150 \mathrm{HP}$ engines. The surveys left daily from Honokohau Harbor on the west side of the island of Hawai'i. General field methods are described by Baird et al. (2013). Recordings were made using digital acoustic recording tags, DTAG3s (Johnson and Tyack, 2003), attached to animals using four small suction cups. Tags sampled stereo audio at a rate of either 240 or $500 \mathrm{kHz}$, with concurrent sampling at $50 \mathrm{~Hz}$ of threedimensional accelerometers, magnetometers, and depth.

DTAG3 deployments were attempted whenever melonheaded whales were encountered. Groups were defined using an $800 \mathrm{~m}$ chain rule (Smolker et al., 1992), i.e., all individuals within $800 \mathrm{~m}$ of any other. Group sizes were estimated including a minimum, maximum and "best" estimate. Individuals in each group encountered were photographed, and photos of distinctive individuals were later compared to a photo-identification catalog to determine population identity (Aschettino et al., 2012). Because no mixing of individuals between populations has been documented, photographic matches to known individuals from one or the other population were used to confirm population identity. Seven tags were deployed in total (mean duration $27 \mathrm{~min}$, range 5-57 min). Only the three longest tag deployments are addressed here, which were 34,42 , and $57 \mathrm{~min}$ long (Table I). Two of these deployments (October 2011 - pe292b and August 2012 - pe237a) were on different members of the KRP and one (May 2012 - pe134a) was on a member of the HIP (Table I, Fig. 1). All groups consisted exclusively of melon-headed whales except in May 2012 when Fraser's dolphins (Lagenodelphis hosei) were identified at the edge of the group. Although they were last seen associated with the melon-headed whale group only $7 \mathrm{~min}$ prior to tag deployment, we believe that they were likely not within $400-500 \mathrm{~m}$ during the period when the tag data were obtained. This is due both to the ease of distinguishing between the two species and the fact that the Fraser's dolphins actively avoided the research vessel at a distance of several hundred meters.

\section{B. Call identification}

Acoustic records were analyzed using a toolbox designed for DTAG analysis and implemented in MATLAB (MathWorks, Natick MA; available at http://soundtags.standrews.ac.uk/dtags/dtag-3/). For each tag recording, data were viewed as consecutive ten-second spectrograms (FFT size 1024 samples, Hamming window 1024 samples, 50\% overlap) with a temporal resolution of $2.1 \mathrm{~ms}$ (pe134a) or 
TABLE I. Details of melon-headed whale group encounters and tag deployments.

\begin{tabular}{|c|c|c|c|c|c|c|c|c|c|}
\hline Date & Population & $\begin{array}{l}\text { Group Size } \\
\text { (best) }\end{array}$ & Start Behavior & End Behavior & Tag ID & Tag On Time & Tag Off Time & $\begin{array}{l}\text { Sample rate } \\
(\mathrm{kHz})\end{array}$ & $\begin{array}{l}\text { Duration } \\
\text { (mm:ss) }\end{array}$ \\
\hline 19-Oct-11 & $\mathrm{KRP}^{\mathrm{a}}$ & 300 & Milling & Milling & pe $292 b$ & $10: 49: 04$ & $11: 23: 41$ & 500 & $34: 37$ \\
\hline 13-May-12 & $\mathrm{HIP}^{\mathrm{b}}$ & 280 & Travel & Travel & pe134a & $15: 57: 04$ & $16: 30: 00$ & 240 & $42: 56$ \\
\hline 24-Aug-12 & $\mathrm{KRP}^{\mathrm{a}}$ & 350 & Slow Travel & Slow Travel & pe237a & $11: 34: 06$ & $12: 31: 45$ & 500 & $57: 39$ \\
\hline
\end{tabular}

${ }^{\mathrm{a}}$ KRP_Kohala Resident Population.

${ }^{\mathrm{b}} \mathrm{HIP}$-Hawaiian Islands Population.

$1 \mathrm{~ms}$ (pe292b and pe237a) and a spectral resolution of $234.8 \mathrm{~Hz}$ (pe134a) or $488.3 \mathrm{~Hz}$ (pe292b and pe237a). Time and frequency resolutions varied among tags as a result of different tag sample rates. All calls, irrespective of amplitude, were marked during a comprehensive audit of each tag recording. We did not attempt to attribute calls to the tagged whale based on call amplitude, because no data are available regarding the range of variability in melon-headed whale call source levels. In total, 1440 calls were marked. Using a custom MATLAB script, these were subsequently excised as individual sound files for further analysis, with an additional $0.1 \mathrm{~s}$ added to the beginning and end of each sound file for signal-to-noise ratio (SNR) calculations.

\section{Acoustic parameters}

All extracted calls were individually imported into MATLAB and amplitude corrected for nominal tag hydrophone sensitivity $(-175 \mathrm{~dB}$ re $1 \mathrm{~V} / \mu \mathrm{Pa})$. In order to maximize SNR, a user-selectable six-pole variable high-pass Butterworth filter (low-frequency cutoff between $300-3000 \mathrm{~Hz}$ ) was implemented to remove low frequency flow and boat noise while retaining the higher frequencies from the signal (Jensen et al., 2011). Noise was calculated by computing the root mean square (RMS) intensity of the last $0.1 \mathrm{~s}$ of each clip and signal duration was defined as the length of the window

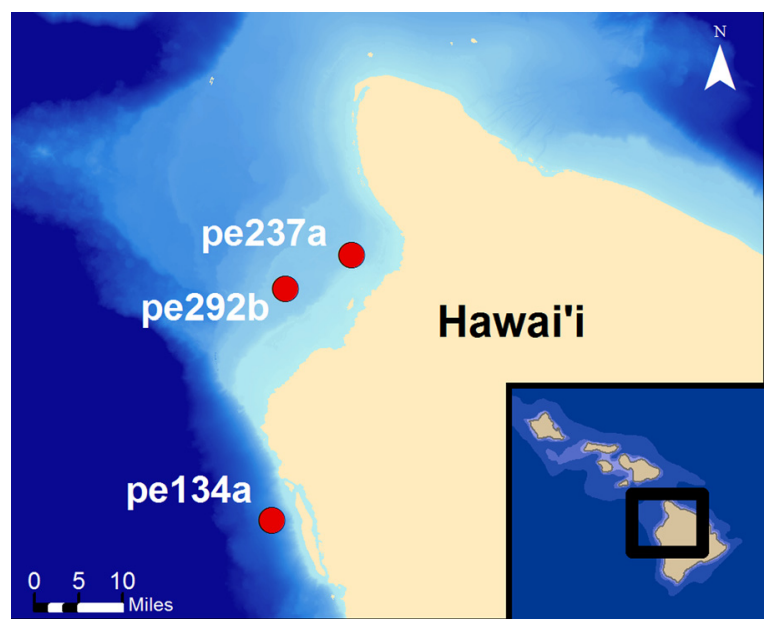

FIG. 1. (Color online) Locations of melon-headed whale tag deployments. Tag pe292b was deployed in October 2011, pe134a in May 2012, and pe237a in August 2012. Both pe292b and pe237a were deployed on members of the KRP, which typically occur in the relatively shallow waters in which they were tagged, whereas pe134a was deployed on a member of the HIP, which occur around all of the main Hawaiian Islands (Aschettino et al. 2012). Data courtesy of Hawaii Mapping Research Group. containing $95 \%$ of the total energy after the noise energy was subtracted (Madsen and Wahlberg, 2007) and excluding the $0.1 \mathrm{~s}$ added to the beginning and end of the clip. Signal-tonoise ratios were then calculated as the difference between RMS signal amplitude and RMS noise amplitude on a decibel scale, and only calls with signal-to-noise ratios greater than $6 \mathrm{~dB}$ were retained (as in Jensen et al., 2012). Of those retained, some were later excluded if there were overlapping calls present. These steps left 457 calls distributed unevenly across the three tags (Table II). The 95\% energy duration of these calls was retained for subsequent statistical analysis.

Calls were visually identified as "tonal" using the spectrogram based on both the presence of concentrations of energy at multiples of one frequency, independent of weighting, as well as the presence of clear start and end frequencies. For these calls start, end, minimum, and maximum frequency of the fundamental were identified interactively using a spectrogram displayed on screen (FFT size 2048 samples, Hamming window 512 samples, 50\% overlap). All other calls were identified as "non-tonal." For tonal and non-tonal calls, power spectral density estimates of the signal were computed using Welch's method (Welch, 1967) by summing the power spectra over the $95 \%$ energy window. Peak frequency, $F_{\mathrm{p}}$ $(\mathrm{Hz})$, the frequency with the highest power, and centroid frequency, $F_{\mathrm{c}}(\mathrm{Hz})$, the frequency that divides the power spectrum into two equal halves, were determined (Au, 1993), and the $-3 \mathrm{~dB}$ and $-10 \mathrm{~dB}$ bandwidths $(\mathrm{kHz})$ of the signals were also computed using Welch's method (Au, 1993; Madsen and Wahlberg, 2007) with a uniform high-pass filter at $500 \mathrm{~Hz}$.

\section{Call categorization and statistical analysis}

Each call for which spectral and temporal parameters were calculated was assigned a random number and stripped of all other identifying information. Spectrograms (FFT size 1024 samples, Hann window 1024 samples, 50\% overlap, dynamic range $\sim 75 \mathrm{~dB}$ ) were printed in grayscale with uniform contrast settings and frequency axes $(0-40 \mathrm{kHz})$ and sized according to duration $(1 \mathrm{~s}=2$ in). Three volunteers with no prior experience with cetacean calls each independently visually categorized the spectrograms. These volunteers were instructed to group the calls into as many categories as they saw fit based on similarities between call contours (Sayigh et al., 2007), but no further instructions were given. When all three volunteers grouped at least two calls together, those calls were combined into a category. All calls that remained after this step (i.e., calls not grouped 
TABLE II. Number of identified, analyzed, omitted, and categorized calls, and number of categories on each tag.

\begin{tabular}{|c|c|c|c|c|c|c|}
\hline Tag ID & $\begin{array}{l}\text { Total Calls } \\
\text { Identified }\end{array}$ & $\begin{array}{l}\text { Analyzed } \\
\text { Calls }\end{array}$ & $\begin{array}{l}\text { Calls Omitted } \\
\text { - Low SNR }\end{array}$ & $\begin{array}{l}\text { Calls Omitted } \\
\text { - Overlapping }\end{array}$ & $\begin{array}{c}\text { Number of } \\
\text { Categorized Calls }\end{array}$ & $\begin{array}{l}\text { Number of } \\
\text { Categories }\end{array}$ \\
\hline pe $292 b$ & 116 & 77 & 33 & 6 & 66 & 10 \\
\hline pe134a & 337 & 35 & 266 & 36 & 4 & 2 \\
\hline pe237a & 987 & 345 & 453 & 189 & 324 & 24 \\
\hline
\end{tabular}

unanimously with another call) were pooled and analyzed together as uncategorized calls.

Call categories were analyzed statistically using MATLAB and $\mathrm{R}$ ( $\mathrm{R}$ Foundation for Statistical Computing, Vienna, Austria). In order to test whether call categories differed significantly from each other spectrally and temporally, a MANOVA was used with call duration, peak frequency, centroid frequency, and $-3 \mathrm{~dB}$ bandwidth as the variables. The test statistic was the Wilks' lambda, which is used to determine how within-sample variation compares to total variation. If $\Lambda$ is small, it indicates that the within-sample variation is low in comparison to the total variation, suggesting that the samples are not drawn from the same population (Manly, 2005). Values of $\Lambda$ were used to compute approximate $F$ statistics, which are reported here. To improve robustness, a randomization test was carried out as follows. Group membership was randomized for each set of call parameters and a new value of $\Lambda$ was computed 1000 times, in order to assess the probability of getting a test statistic greater than or equal to the observed value by chance.

In order to determine whether calls of a given type were more likely to occur in sequences than would be expected by chance, the probability that a given call type would be followed by the same call type was calculated, and then compared to probabilities derived from randomized distributions. First, the total number of times that a call type was directly followed by that same call type was computed for each tag (i.e., "transitions" from call type $i$ to call type $i$ ). This value was divided by the total number of calls minus one on that tag to get the observed percentage of transitions where a call of a given type was followed by another call of the same type. For this analysis, all 1440 calls identified on the tag records were used. Unanalyzed calls and uncategorized calls (i.e., calls for which parameters were available but that were not grouped with other calls) were collectively considered to be "unknown" calls. These unknown calls served solely as placeholders in time. Timing information was then randomized 1000 times by fixing the positions of unknown calls and randomizing the positions of categorized calls. For each iteration, the percentage of like call-to-call transitions was computed as described above. Then, the total number of randomization test statistics with results greater than or equal to the observed value was divided by the total number of iterations to determine the likelihood that the observed result arose by chance.

\section{RESULTS}

In total, 36 categories of unique call types with more than two calls emerged, accounting for $>85 \%$ of all calls (394; Fig. 2). Of these 36 categories, 11 contained only two calls and 16 contained five or more calls. These 16 categories occurred only on the two tagged KRP whales, with 11 occurring on tag pe237a, which had the longest recording duration, and five on pe292b. Figure 3 shows four categories of calls, two each from the KRP tags, with three examples per category. An additional six uncategorized calls randomly selected from all three tags are shown (out of a total of 63 uncategorized calls). Only two categories emerged from the HIP whale and each of these categories contained only two calls. No categories contained calls from multiple tags and consequently there were no shared call types among tags. However, the two KRP groups did have many individuals in common: Of the 26 individuals that were photo-identified from the October 2011 encounter (group size of 300), 16 were also identified in the August 2012 encounter (group size of 350).

Call categories differed significantly from each other in duration, peak and centroid frequency, and $-3 \mathrm{~dB}$ bandwidth (MANOVA: $F_{4,338}=32.764, p<0.001$ ). Of these four variables, only duration and peak frequency were significant contributors to the between-category differences. The results of the randomization test confirm that the probability of this result arising by chance was less than 0.001 , which indicates that there were significant parameter differences among the observer categories.

Calls of a given category followed each other significantly more often than would be expected by chance [observed (expected) proportion of consecutive calls: pe292b $=0.165$ (0.065), $\quad p<0.0001 ; \quad$ pe237a $=0.036$ (0.024), $\quad p<0.004]$. Because only four calls (two categories) were categorized on the HIP tag, it was not included in this analysis.

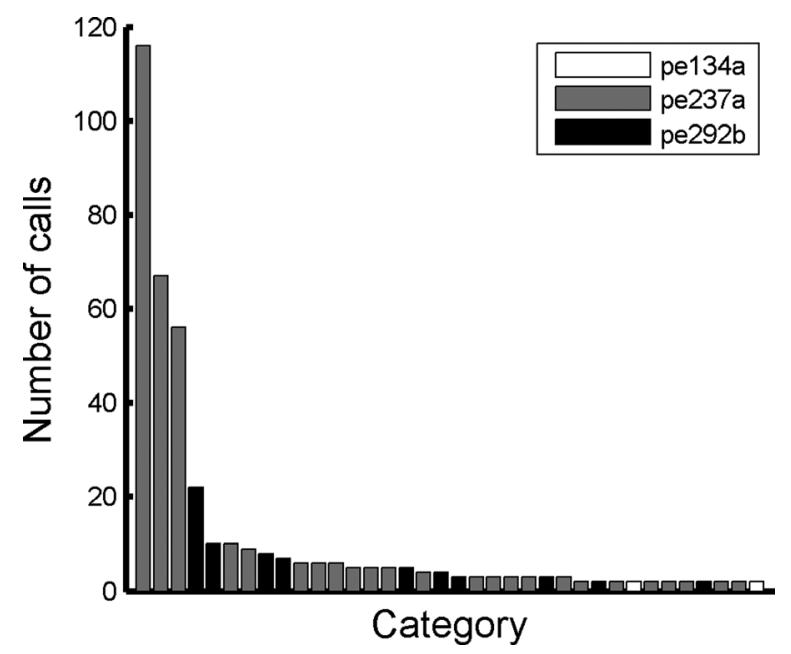

FIG. 2. Number of melon-headed whale calls in each category. Most categories emerged from tag pe237a (gray), and the fewest were from pe124a (white). 


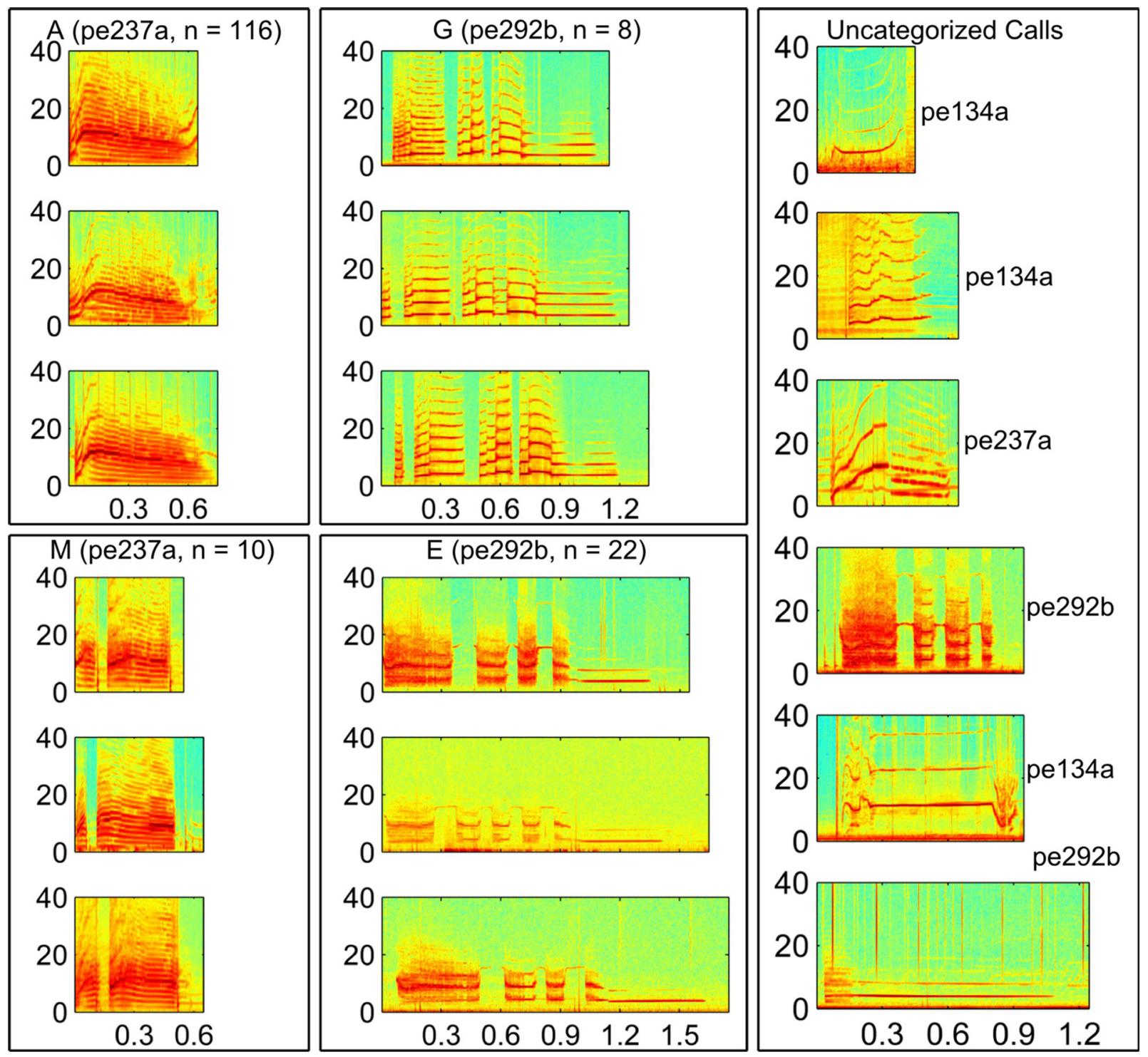

FIG. 3. (Color online) Melon-headed whale call spectrograms (and total number of calls per category) from four categories (A, M, G, and E) and 6 randomly selected uncategorized calls (UC), which are identified by tag origin (e.g., pe237a).

Tonal calls were identified on all tags, including all analyzed calls from the HIP tag (pe134a: 35/35) and a proportion of calls on the two KRP tags (pe292b: 42/77; pe237a: 74/335; Fig. 4). Spectral and temporal characteristics of all tonal and non-tonal calls (pooled across all

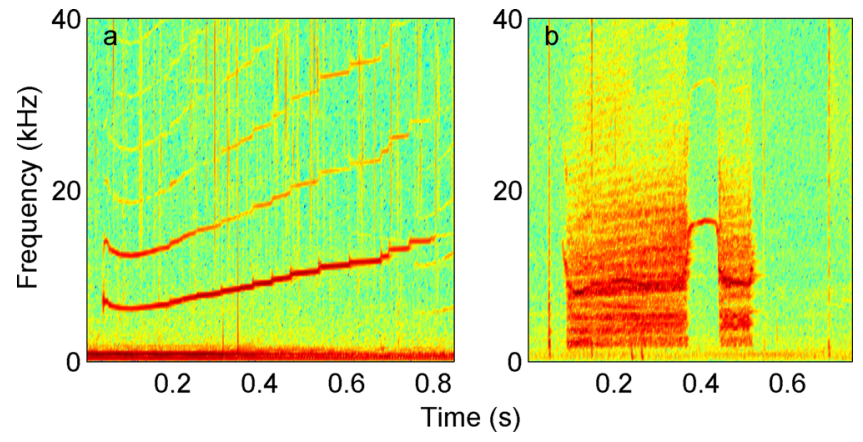

FIG. 4. (Color online) (a) Tonal and (b) non-tonal melon-headed whale call examples that are indicative of the overall differences between these types of calls. three tags) were compared to each other and to the parameters described by Frankel and Yin (2010), who only identified tonal calls (Table III). Durations were similar across call types. Start, end, minimum, and maximum

TABLE III. Comparison of tonal and non-tonal call parameters between this study and that of Frankel and Yin (2010), who did not distinguish between call types. Dashes indicate missing data that either could not be or were not calculated.

\begin{tabular}{lccc}
\hline \hline & $\begin{array}{c}\text { Tonal Calls } \\
(\mathrm{n}=151)\end{array}$ & $\begin{array}{c}\text { Non-tonal Calls } \\
(\mathrm{n}=306)\end{array}$ & $\begin{array}{c}\text { Frankel and Yin 2010 } \\
(\mathrm{n}=363)\end{array}$ \\
\hline Duration $(\mathrm{s})$ & $0.5 \pm 0.3$ & $0.5 \pm 0.3$ & $0.6 \pm 0.3$ \\
$\mathrm{~F}_{\text {start }}(\mathrm{kHz})$ & $5.06 \pm 3.75$ & - & $6.08 \pm 2.36$ \\
$\mathrm{~F}_{\text {end }}(\mathrm{kHz})$ & $9.86 \pm 6.1$ & - & $9.59 \pm 5.88$ \\
$\mathrm{~F}_{\min }(\mathrm{kHz})$ & $3.49 \pm 1.69$ & - & $5.31 \pm 1.8$ \\
$\mathrm{~F}_{\max }(\mathrm{kHz})$ & $12.62 \pm 6.04$ & - & $10.77 \pm 4.35$ \\
$F_{\mathrm{p}}(\mathrm{kHz})$ & $7.37 \pm 3.18$ & $9.92 \pm 2.32$ & - \\
$F_{\mathrm{c}}(\mathrm{kHz})$ & $9.83 \pm 7.13$ & $9.87 \pm 2.53$ & - \\
$-3 \mathrm{~dB} \mathrm{BW}(\mathrm{kHz})$ & $2.6 \pm 3.07$ & $3.03 \pm 1.58$ & - \\
$-10 \mathrm{~dB} \mathrm{BW}(\mathrm{kHz})$ & $6.07 \pm 1.09$ & $4.66 \pm 2.13$ & - \\
\hline \hline
\end{tabular}




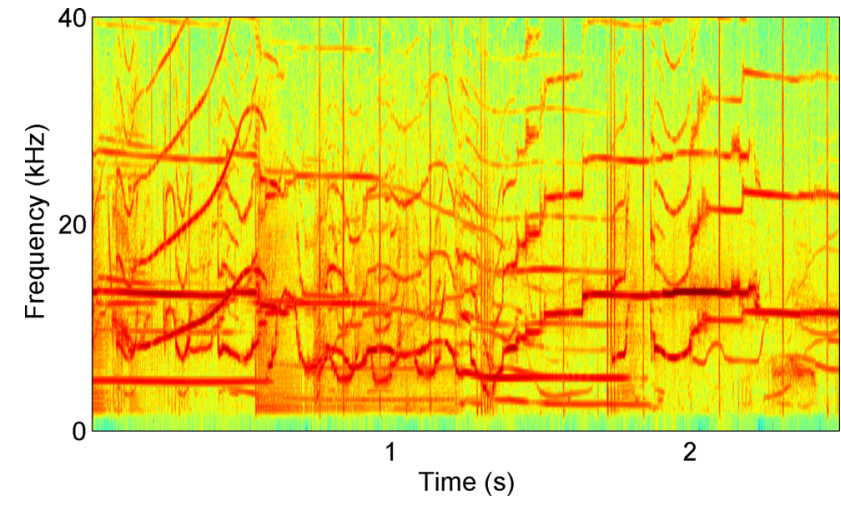

FIG. 5. (Color online) Spectrogram illustrating multiple overlapping calls, taken from the pe 237 tag record.

frequencies were similar between tonal calls identified here and those identified by Frankel and Yin (2010), although frequency range (max-min) was greater in the present investigation.

\section{DISCUSSION}

These data show that repeated call types comprise a considerable proportion of calls recorded on tagged melonheaded whales. Although only $32 \%$ of recorded calls were analyzed, the majority of these calls were unanimously grouped together with at least one other call by three naive volunteers. Call category membership is conservative because it required unanimous agreement among the judges; thus, the number of repeated calls may be underestimated. Categories differed significantly from each other both spectrally and temporally, supporting the judges' classifications.

No categories of repeated call types contained calls from multiple tags. Given that there was overlap in membership between the two KRP groups, this finding suggests that these calls may be individually or sub-group specific. Because of the close proximity of multiple animals within a subgroup (often less than a body length), it was not possible to determine whether repeated calls came from the tagged individual and/or nearby conspecifics. Research employing concurrent DTAGs on multiple animals will be necessary to address whether melon-headed whales produce individually specific calls. It is also possible that calls may be shared at the subgroup level, but little is currently known about potential subgroup structure in melon-headed whales, so this also remains an avenue for further research. Although our sample size is small, our data do not provide evidence for the idea that melon-headed whales produce shared, group-specific calls like those seen in fish-eating "resident" killer whales (Ford, 1989).

Calls in a given category were produced consecutively more often than would be expected by chance. Sequences of repeated calls can serve a variety of functions. They may be a feature of a particular call type, such as the individually specific signature whistles of common bottlenose dolphins, which are often repeated in a stereotyped bout structure separated by intervals of 1-10s (Janik et al., 2013). Repeated call sequences may also result from call matching or exchanges of the same call type among two or more individuals. Another function for repeated calling may be to enhance detection probabilities in a noisy environment. Several previous studies have documented changes to calling behavior based on background noise characteristics. Japanese quails (Coturnix coturnix japonica) increased their crowing rate and king penguins (Aptenodytes patagonicus) increased their call rate with increased ambient noise (Potash, 1972; Lengagne et al., 1999). Humpback whales (Megaptera novaeangliae) increased the duration of song bouts in the presence of low-frequency active sonar (Miller et al., 2000), and blue whales (Balaenoptera musculus) increased their calling rate during seismic surveys (Di Iorio and Clark, 2010). In our study, tagged animals were members of groups of 280-350 individuals, and overlapping calls of multiple types occurred frequently, likely as a result of high overall call rates in the group (Fig. 5). This high call density has also been noted in other recordings of melon-headed whales (Frankel and Yin, 2010). Thus, sequences of repeated calls may reduce masking by background noise, including sounds produced by conspecifics, thereby increasing the potential for successful detection (Brumm and Slater, 2006). However, the possibility that effects of tagging may have elicited anomalous call production cannot be ruled out. Thus, additional data from longer duration tags are needed in order to disentangle the effects of tagging from natural communication behavior.

Approximately two-thirds of all calls that were identified on the tag recordings could not be analyzed as a result of low SNR or presence of overlapping calls. Thus, it is possible that different trends might emerge from our dataset if a more comprehensive analysis were carried out. However, these "unknown" calls were taken into account when calculating the probability with which known call types followed each other consecutively. Therefore, this measure of probability is conservative (i.e., likely to underestimate call repetition) because it is possible that some or many of these "unknown" calls may also be repeated call types, which would increase the chance of a call being followed by another of the same type.

Differences between the HIP and KRP tags could result from sample size effects, population differences, or a variety of contextual variables, such as season, time of day, and group composition or activity. Although the present sample size is too small to look for population-level differences in call production, the higher proportion of tonal calls on the HIP tag as compared to the KRP tags is interesting, and warrants further study. Social network analyses of photographed individuals suggest very low rates of interchange between the KRP and the HIP (Aschettino et al., 2012). Differentiation in acoustic behavior among sympatric populations might be expected if individuals benefit from preferentially associating with members of their population and if interchange between populations is low. However, the different behaviors observed during the various encounters (milling, travel, slow travel; Table I) could also lead to differences in calling behavior. Thus, additional recordings of members of both populations will be required to confirm or refute the observed difference. 
Spectral and temporal parameters measured from tonal calls pooled across tags are similar to those reported by Frankel and Yin (2010). However, there is considerable variation around the mean in all measured variables in both studies. As such, solely comparing mean spectral values among species does not adequately address within-species variation. Thus, in contrast to the suggestion of Frankel and Yin (2010), our results suggest that means alone would not be sufficient to discriminate melon-headed whale calls from those of some other odontocetes. In addition, spectral and temporal analysis of odontocete calls should take into account the potential for repeated call types to bias assessments of population-level call parameters. Given that call category parameters differed significantly from each other, if one category dominated a recording, the overall parameterization of calls could be skewed. Thus, future investigations that seek to parameterize species- or population-specific calls should ensure that recordings are not dominated by a small number of call types.

This investigation presents the first evidence for repeated calls in melon-headed whales, adding it to a growing list of delphinid species that produce such call types. We suggest that this type of calling behavior may either be an inherent feature of certain call types (e.g., signature, subgroup or group specific calls), and/or it may serve to enhance detection probabilities in large groups of animals with many overlapping calls. Additional data collection will be required to better resolve individual- and population-level differences in the acoustic behavior of this species, and in order to derive accurate automatic detection and classification algorithms to inform passive acoustic monitoring efforts that are of growing importance in marine mammal conservation.

\section{ACKNOWLEDGMENTS}

This project was funded by the Office of Naval Research (award number: N000141110612; Program Manager Michael J. Weise), WHOI Marine Mammal Center, and the Sawyer and Penzance Endowed Funds, with additional field time funded by grants through Cascadia Research Collective by the National Oceanographic Partnership Program (through the Alaska SeaLife Center) and the Pacific Islands Fisheries Science Center. Daniel Webster deployed the tags. Jessica Aschettino confirmed the population identity of groups encountered. Paul Nachtigall and Peter Tyack assisted with project planning. We thank Peter Tyack, Michael Moore, Judy Layzer, and Frants Jensen for helpful advice on various stages of this work. We are also grateful to Deb Robbins, Andrea Schlunk, and Tammy Silva for their help in classifying calls. Andy Solow gave valuable statistical advice. Employees of Cascadia Research Collective and other volunteers provided assistance in the field. Tagging took place under NMFS permit \# 15530 to Cascadia Research Collective and WHOI Institutional Animal Care and Use Committee approval (BI15245.00).

Antunes, R., Schulz, T., Gero, S., Whitehead, H., Gordon, J., and Rendell, L. (2011). "Individually distinctive acoustic features in sperm whale codas," Anim. Behav. 81, 723-730.
Aschettino, J. M., Baird, R. W., McSweeney, D. J., Webster, D. L., Schorr, G. S., Huggins, J. L., Martien, K. K., Mahaffy, S. D., and West, K. L. (2012). "Population structure of melon-headed whales (Peponocephala electra) in the Hawaiian Archipelago: Evidence of multiple populations based on photo identification," Mar. Mamm. Sci. 28, 666-689.

Au, W. W. L. (1993). The Sonar of Dolphins (Springer, New York), 277 pp. Baird, R. W., Webster, D. L., Aschettino, J. M., Schorr, G. S., and McSweeney, D. J. (2013). "Odontocete Cetaceans around the main Hawaiian Islands: Habitat use and relative abundance from small-boat sighting surveys," Aquat. Mamm. 39, 253-269.

Bradbury, J. W., and Vehrencamp, S. L. (1998). Principles of Animal Communication (Sinauer Associates, Inc., Sunderland, MA), 882 pp.

Brownell, R. L., Ralls, K., Baumann-Pickering, S., and Poole, M. M. (2009). "Behavior of melon-headed whales, Peponocephala electra, near oceanic islands," Mar. Mamm. Sci. 25, 639-658.

Brumm, H., and Slater, P. J. B. (2006). "Ambient noise, motor fatigue, and serial redundancy in chaffinch song," Behav. Ecol. Sociobiol. 60, $475-481$.

Caldwell, M. C., and Caldwell, D. K. (1965). "Individualized whistle contours in bottlenosed dolphins (Tursiops truncatus)," Nature 207, 434-435.

Caldwell, M. C., and Caldwell, D. K. (1968). "Vocalization of naive Dolphins in small groups," Science 159, 1121-1123.

Caldwell, M. C., Caldwell, D. K., and Miller, F. J. (1973). "Statistical evidence for individual signature whistles in the spotted dolphin, Stenella plagiodon," Cetology 3, 1-9.

Caldwell, M. C., Caldwell, D. K., and Tyack, P. L. (1990). "Review of the signature-whistle hypothesis for the atlantic bottlenose dolphin," in The Bottlenose Dolphin (Academic Press, Inc.), pp. 199-234.

de Figueiredo, L. D., and Simao, S. M. (2009). "Possible occurrence of signature whistles in a population of Sotalia guianensis (Cetacea, Delphinidae) living in Sepetiba Bay, Brazil," J. Acoust. Soc. Am. 126, 1563-1569.

Di Iorio, L., and Clark, C. W. (2010). "Exposure to seismic survey alters blue whale acoustic communication," Biol. Lett. 6, 51-54.

Ford, J. K. B. (1989). "Acoustic behaviour of resident killer whales (Orcinus orca) off Vancouver Island, British Columbia,” Can. J. Zool. 67, $727-745$.

Frankel, A. S., and Yin, S. (2010). "A description of sounds recorded from melon-headed whales (Peponocephala electra) off Hawai'i," J. Acoust. Soc. Am. 127, 3248-3255.

Gridley, T., Cockcroft, V. G., Hawkins, E. R., Blewitt, M. L., Morisaka, T., and Janik, V. M. (2014). "Signature whistles in free-ranging populations of Indo-Pacific bottlenose dolphins, Tursiops aduncus," Mar. Mamm. Sci. 30, 512-527.

Janik, V. M. (2005). "Underwater acoustic communication networks in marine mammals," in Animal Communication Networks, edited by P. K. McGregor (Cambridge University Press, Cambridge, UK), pp. 390-415.

Janik, V. M. (2009). "Acoustic Communication in Delphinids," in Vocal Communication in Birds and Mammals, edited by M. Naguib, V. Janik, N. Clayton, and K. Zuberbuhler (Academic Press), pp. 123-157.

Janik, V. M., King, S. L., Sayigh, L. S., and Wells, R. S. (2013). "Identifying signature whistles from recordings of groups of unrestrained bottlenose dolphins (Tursiops truncatus)," Mar. Mamm. Sci. 29, 109-122.

Janik, V. M., and Sayigh, L. S. (2013). "Communication in bottlenose dolphins: 50 years of signature whistle research," J. Comp. Physiol. A Neuroethol. Sens. Neural. Behav. Physiol. 199, 479-489.

Janik, V. M., Sayigh, L. S., and Wells, R. S. (2006). "Signature whistle shape conveys identity information to bottlenose dolphins," Proc. Natl. Acad. Sci. U.S.A. 103, 8293-8297.

Janik, V. M., and Slater, P. J. B. (1998). "Context-specific use suggest that bottlenose dolphin signature whistles are cohesion calls," Anim. Behav. 56, 829-838.

Jefferson, T. A., and Barros, N. B. (1997). "Peponocephala electra," Mamm. Spec. 553, 1-6.

Jensen, F. H., Beedholm, K., Wahlberg, M., Bejder, L., and Madsen, P. T. (2012). "Estimated communication range and energetic cost of bottlenose dolphin whistles in a tropical habitat," J. Acoust. Soc. Am. 131, 582-592.

Jensen, F. H., Perez, J. M., Johnson, M., Soto, N. A., and Madsen, P. T. (2011). "Calling under pressure: Short-finned pilot whales make social calls during deep foraging dives," Proc. Biol. Sci. 278, 3017-3025.

Johnson, M. P., and Tyack, P. L. (2003). "A digital acoustic recording tag for measuring the response of wild marine mammals to sound," IEEE J. Ocean. Eng. 27, 3-12. 
Lengagne, T., Aubin, T., Lauga, J., and Jouventin, P. (1999). "How do king penguins (Aptenodytes patagonicus) apply the mathematical theory of information to communicate in windy conditions?," Proc. R. Soc. B 266, 1623-1628.

Madsen, P. T., and Wahlberg, M. (2007). "Recording and quantification of ultrasonic echolocation clicks from free-ranging toothed whales," Deep Sea Res. Part I Oceanogr. Res. Pap. 54, 1421-1444.

Manly, B. F. J. (2005). Multivariate Statistical Methods: A Primer (Chapman \& Hall/CRC, Boca Raton, FL), 208 pp.

Mann, J. (2000). Cetacean Societies: Field Studies of Dolphins and Whales (University of Chicago Press, Chicago, IL), 448 pp.

Miller, P. J. O., Biassoni, N., Samuels, A., and Tyack, P. L. (2000). "Whale songs lengthen in response to sonar," Nature 405, 903.

Morisaka, T., Yoshida, Y., Akune, Y., Mishima, H., and Nishimoto, S. (2013). "Exchange of "signature" calls in captive belugas (Delphinapterus leucas)," J. Ethol. 31, 141-149.

Murray, S. O., Mercado, E., and Roitblat, H. L. (1998). "Characterizing the graded structure of false killer whale (Pseudorca crassidens) vocalizations," J. Acoust. Soc. Am. 104, 1679-1688.

Potash, L. M. (1972). "Noise-induced changes in calls of the Japanese quail," Psychon. Sci. 26, 252-254.

Quick, N. J., and Janik, V. M. (2012). "Bottlenose dolphins exchange signature whistles when meeting at sea," Proc. Biol. Sci. 279, 2539-2545.

Rankin, S., Oswald, J., Barlow, J., and Lammers, M. (2007). "Patterned burst-pulse vocalizations of the northern right whale dolphin, Lissodelphis borealis," J. Acoust. Soc. Am. 121, 1213-1218.

Sayigh, L. S., Esch, H. C., Wells, R. S., and Janik, V. M. (2007). "Facts about signature whistles of bottlenose dolphins, Tursiops truncatus," Anim. Behav. 74, 1631-1642.

Sayigh, L. S., Quick, N., Hastie, G., and Tyack, P. (2013). "Repeated call types in short-finned pilot whales, Globicephala macrorhynchus," Mar. Mamm. Sci. 29, 312-324.

Sayigh, L. S., Tyack, P. L., Wells, R. S., and Scott, M. D. (1990). "Signature whistles of free-ranging bottlenose dolphins Tursiops truncatus: Stability and mother-offspring comparisons," Behav. Ecol. Sociobiol. 26, 247-260.
Sayigh, L. S., Tyack, P. L., Wells, R. S., Solow, A. R., Scott, M. D., and Irvine, A. B. (1999). "Individual recognition in wild bottlenose dolphins: A field test using playback experiments," Anim. Behav. 57, 41-50.

Sekiguchi, K., Klages, N. T. W., and Best, P. B. (1992). "Comparative analysis of the diets of smaller odontocete cetaceans along the coast of southern Africa," Afr. J. Mar. Sci. 12, 843-861.

Shapiro, A. D. (2006). "Preliminary evidence for signature vocalizations among free-ranging narwhals (Monodon monoceros)," J. Acoust. Soc. Am. 120, 1695-1705.

Smolker, R. A., Richards, A. F., Connor, R. C., and Pepper, J. W. (1992). "Sex differences in patterns of association among Indian Ocean bottlenose dolphins," Behavior 123, 38-69.

Southall, B. L., Braun, R., Gulland, A. D., Baird, R. W., Wilkin, S. M., and Rowles, T. K. (2006). "Hawaiian Melon-headed whale (Peponocephala electra) mass stranding event of July 3-4, 2004," NOAA Technical Memorandum NMFS-OPR-31 April 2006, 73 pp.

Southall, B. L., Rowles, T. K., Gulland, F., Baird, R. W., and Jepson, P. D. (2013). "Final report of the Independent Scientific Review Panel investigating potential contributing factors to a 2008 mass stranding of melonheaded whales (Peponocephala electra) in Antsohihy, Madagascar," 75 pp.

Van Parijs, S. M., and Corkeron, P. J. (2001). "Evidence for signature whistle production by a Pacific humpback dolphin, Sousa chinensis," Mar. Mamm. Sci. 17, 944-949.

Watkins, W. A., Daher, M. A., Samuels, A., and Gannon, D. P. (1997). "Observations of Peponocephala electra, the Melon-headed Whale, in the Southeastern Caribbean," Caribb. J. Sci. 33, 34-40.

Welch, P. D. (1967). "The use of fast fourier transform for the estimation of power spectra: A method based on time averaging over short, modified periodograms," IEEE Trans. Acoust. AU-15, 70-73.

Woodworth, P. A., Schorr, G. S., Baird, R. W., Webster, D. L., McSweeney, D. J., Hanson, M. B., Andrews, R. D., and Polovina, J. J. (2012). "Eddies as offshore foraging grounds for melon-headed whales (Peponocephala electra)," Mar. Mamm. Sci. 28, 638-647.

Yurk, H., Barrett-Lennard, L., Ford, J. K. B., and Matkin, C. O. (2002). "Cultural transmission within maternal lineages: Vocal clans in resident killer whales in southern Alaska," Anim. Behav. 63, 1103-1119. 